\title{
The 400-m Front Crawl Test: Energetic and 3D Kinematical Analyses
}

\author{
Authors \\ Ricardo de Assis Correia', Wellington Gomes Feitosa ${ }^{1,2}$, Pedro Figueiredo ${ }^{3}$, Marcelo Papoti ${ }^{4}$, \\ Flávio Antonio de Souza Castro ${ }^{1}$
}

\section{Affiliations}

1 School of Physical Education, Universidade Federal do Rio Grande do Sul, Porto Alegre, Brazil

2 Faculty of Physical Education, Universidade Estadual do Ceará, Fortaleza, Brazil

3 Health Sciences and Human Development, University Institute of Maia, Castelo da Maia, Portugal

4 School of Physical Education and Sport of Universidade de São Paulo, Ribeirão Preto, Ribeirão Preto, Brazil

\section{Key words}

swimming, metabolic systems, energy cost, anaerobic contribution, center of mass speed

accepted $\quad 25.09 .2019$

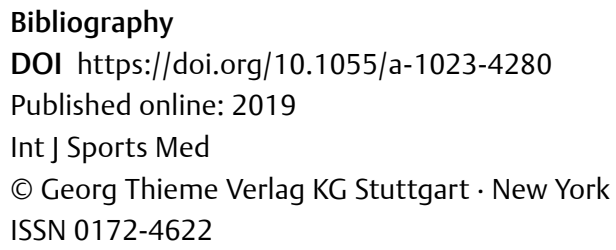

\begin{abstract}
The aim of the study was to verify the relative contributions of energetic and kinematic parameters to the performance in 400$\mathrm{m}$ front crawl test. Fourteen middle-distance swimmers participated in the study. Oxygen consumption was measured directly and blood samples were collected to assay lactate concentration. Both oxygen consumption and lactate concentration were used to calculate the: (i) overall energy expenditure, (ii) anaerobic (alactic and lactic) and (iii) aerobic contributions. The mean centre of mass speed and intracycle velocity variation were determined through three-dimensional kinematic analysis. Mean completion time was $315.64 \pm 26.91 \mathrm{~s}$. Energetic contributions were as follows: $6.1 \pm 0.28 \%$ from alactic anaerobic metabolism, $5.9 \pm 0.63 \%$ from anaerobic lactic and $87.8 \pm 0.88 \%$ from aerobic. Mean intracycle velocity variation was $0.14 \pm 0.03$. The results indicated that performance of 400 - $m$ test relies predominantly on aerobic power. Parameters such as lactate, mean speed, anaerobic lactic and alactic $(\mathrm{kW})$ correlated with performance of $400-m$ test $(p<0.05)$. Multiple linear regressions indicated that mean centre of mass speed and anaerobic alactic $(\mathrm{kW})$ determined the $400-\mathrm{m}$ test performance $\left(R^{2}=0.92\right)$. Even though the T400 is characterized by aerobic metabolism, the anaerobic alactic component cannot be negligible at this competition level.
\end{abstract}

\section{Introduction}

Assessment of physiological parameters during swimming remains a challenge. For environmental reasons it is not as easy to measure oxygen uptake $\left(\mathrm{VO}_{2}\right)$, for example, as it is in other cyclical sports [1]. The 400-m all-out front crawl test (T400) has been proposed as a viable and economic alternative to more complex tests for obtaining information about swimmers' aerobic capacity (total amount of energy) and are currently considered valid for evaluating aerobic power $\left(\mathrm{VO}_{2} \mathrm{max}\right)[2,3]$. The literature indicates that $70-80 \%$ of the energy sources come from the aerobic contribution and $30-20 \%$ from the anaerobic contribution [4-6] for the T400.
However, there are few studies that have measured $\mathrm{VO}_{2}$ directly during the T400 [3, 7]. It is possible to find data from T400 studies based on retro-extrapolation from the recovery curve [13] or obtained in dry-land ergometers [8], or in a swimming flume [9]. In addition, the different estimates (e.g., equations, units of measurement, and predictive values) used to estimate energy sources (ES) parameters make comparisons difficult [10].

Although the aerobic contribution to T400 performance is very important, one cannot ignore the anaerobic (alactic and lactic) contributions $[6,11]$ to ES and performance. Moreover, the energy cost $(C)$, as the ratio between ES and swimming speed, is the en- 
ergy expenditure per unit of distance swum [12]. C is influenced by hydrodynamic drag, age, and training experience [13,14], and it is accepted as the best indicator of performance in middle- and longdistance competitive events. Further investigation of the T400 is necessary to describe the complete energy balance and its relationship to performance. In addition, the T400 (as a square-wave test) allows identifying the oxygen uptake peak ( $\mathrm{VO}_{2}$ peak), which can be considered a value similar to the $\mathrm{VO}_{2} \max [3,7]$.

The intracycle velocity variation (IVV) has also been identified as an important $C$ predictor because it describes the speed fluctuations resulting from changes in thrust and drag during one arm stroke [13]. Moreover, the technical level of the swimmer and the distance travelled can also interfere in these variations. In welltrained swimmers, IVV in a 200-m front crawl test (swimming speed $\sim 1.41 \mathrm{~m} \cdot \mathrm{s}^{-1}$ ) was 0.22 when measured using the three-dimensional motion analysis system method [15]. In a T400, IVV was $\sim 0.14$ when measured with the two-dimensional motion analysis system method [16]. To the best of our knowledge, there is not, however, a study that provides matching IVV and physiological data for the T400.

Little is known about ES and C values derived from direct measurements of $\mathrm{VO}_{2}$ in the T400, besides the studies of Zacca and colleagues $[3,7]$. To our knowledge, this is the first study to examine $\mathrm{ES}, \mathrm{C}$, and IVV in the T400 in adult competitive swimmers. Considering the possible relations between the ES, the T400 three-dimensional center-of-mass mean speed (S400), and IVV, the purpose of this study was to verify the relative contributions of these parameters to the performance in 400-m front crawl test. Our hypothesis was that although T400 is predominantly based on aerobic metabolism, anaerobic metabolism also makes an important contribution to performance in this test. In relation to kinematical parameters, the $\$ 400$ is the only parameter that explains the performance of the T400.

\section{Materials and Methods}

\section{Subjects}

Fourteen male swimmers with experience in middle- and long-distance races at national and international championships participated in this study (means and SDs: age, $23 \pm 5$ years old; height, $176 \pm 4.5 \mathrm{~cm}$; arm span. $183 \pm 5 \mathrm{~cm}$; body mass, $71.6 \pm 5.9 \mathrm{~kg}$; training background, $12.5 \pm 5$ years; $77.15 \pm 3.6 \%$ of the world record in men's 400-m freestyle on a short course). In addition, most swimmers performed very similarly in the 400-m front crawl. The swimmers were all in the same training period: post major competition of the year and used to training 6-9 times per week, 90-150 min per session. The swimmers spent two weeks familiarizing themselves with the test procedures and equipment (AquaTrainer ${ }^{\circledR}$ snorkel, Cosmed, Rome, Italy) before the test. Participants were asked to abstain from intense physical effort and/or training for $48 \mathrm{~h}$ before the test. The study conformed to the standards set by the Declaration of Helsinki, and the local Institutional Review Board approved the procedures. In addition, the study met the ethical standards of this journal [17]. Written informed consent was obtained from all participants.

\section{Experimental procedure}

Each swimmer performed the test once in a $25-\mathrm{m}$ indoor pool ( $1.90 \mathrm{~m}$ deep, water temperature between 29 and $30^{\circ} \mathrm{C}$ ). Participants warmed up by swimming $800-\mathrm{m}$, consisting of $600-\mathrm{m}$ at low intensity, as in competition warm-ups but with open turns; followed by $200-\mathrm{m}$ of front crawl with the snorkel. The test was a T400 simulating the 400-m freestyle event with an in-water start and open turns.

\section{Energetic parameters}

$\mathrm{VO}_{2}$ during the $\mathrm{T} 400$ was measured directly, breath-by-breath, using a telemetric portable gas analyzer ( $\mathrm{K} 5$; Cosmed, Rome, Italy) connected to a snorkel and valve system (AquaTrainer ${ }^{\circledR}$, Cosmed) suspended $\sim 2 \mathrm{~m}$ above the water's surface by a steel cable. The telemetric portable gas analyzer was calibrated before each testing session with gases of known concentration $\left(16 \% \mathrm{O}_{2}\right.$ and $\left.5 \% \mathrm{CO}_{2}\right)$ and the turbine volume transducer calibrated with a 3-liter syringe. Data were pre-processed to exclude errant breaths (swallowing, coughing, and/or signal interruptions) by including only those within 4 SD of the mean [18]. The data were then smoothed using a 5-breath moving window [19]. Peak oxygen uptake $\left(\mathrm{VO}_{2 \text { peak }}\right)$ was defined as the highest value of the curve during the T400 [20]. Oxygen uptake and lactate concentration at rest $\left(\mathrm{VO}_{2 \text { rest }}\right.$ and $\mathrm{La}_{\text {rest }}$, respectively) were measured before the T400 (after warm-up), and afterwards after 5 to 10 min of rest with the body (except the head) submerged in the water. $\mathrm{VO}_{2 \text { rest }}$ was the $\mathrm{VO}_{2}$ in which the respiratory exchange ratio stabilized at approximately 0.8 . Venous blood $(5 \mu \mathrm{L})$ was collected from the antecubital region and used to determine lactate concentration, which was measured at rest and after exercise (1, 3 , 5 , and $7 \mathrm{~min}$ after the test) in order to determine the peak lactate value $\left(\mathrm{La}_{\text {peak }}\right)$. Blood lactate concentration was determined by means of enzymatic analyses with a specific reagent (Lactate K084; Bioclin, Santa Branca, Brazil) followed by a reading in a biochemical analyzer (SINOWA SX-140; Hemobio, São Paulo, Brazil).

\section{Energetic contribution and cost}

The parameters of aerobic and anaerobic metabolism during T400 ( $\triangleright$ Equation 1) were calculated by the total energy expenditure equation $[10,12,15,21]$ :

$E_{\text {tot }}=\mathrm{VO}_{2}+\beta \mathrm{La}_{\mathrm{b}}+\mathrm{PCr}\left(1-\mathrm{e}^{-\mathrm{t} / \tau}\right)$

where $E_{\text {tot }}$ is the overall energy expenditure over the $T 400 ; \mathrm{VO}_{2}$ was calculated from the time-integral of the net difference between $\mathrm{VO}_{2 \text { peak }}$ and $\mathrm{VO}_{2 \text { rest }}$ and used to estimate the aerobic contribution (Aer, $\mathrm{kJ}$ ), assuming an energy equivalent of $20.9 \mathrm{k} \cdot \mathrm{J} \cdot 1 \mathrm{O}_{2}{ }^{-1}$ (Zamparo et al. 2010). $L a_{b}$ is the difference between $L_{a}$ peak and $L a_{\text {rest }}$, multiplied by $\beta=2.7 \mathrm{ml} \cdot \mathrm{O}_{2} \cdot \mathrm{mM}^{-1} \mathrm{~kg}^{-1}$ and then by the total body mass $(\mathrm{kg})$ to yield the lactic anaerobic contribution (AnLa, kJ), assuming an energy equivalent of $20.9 \mathrm{k} \cdot \mathrm{J} \cdot \mathrm{IO}_{2}{ }^{-1}$ (Zamparo et al. 2010). PCr (AnAla, kJ) was estimated from the concentration of phosphocreatine of $18.55 \mathrm{mM} \cdot \mathrm{kg}^{-1}$ (net weight at maximum muscle activation, assuming $30 \%$ of muscle mass activated) [12, 22]. $\mathrm{t}$ is time duration and $\mathrm{T}$ is time constant of $\mathrm{PCr}$ splitting at work onset (23.4 s as proposed by Binzoni, Ferretti, Schenker, et al. [23]). Both Aer and AnLa were expressed in kJ assuming an energetic equivalent of $20.9 \mathrm{~kJ} \mathrm{IO}_{2}^{-1}$. AnAl can be expressed in $\mathrm{kJ}$ by assuming a $\mathrm{P} / \mathrm{O}_{2}$ ratio of 6.25 and an energy equivalent of 
$0.468 \mathrm{~kJ} \cdot \mathrm{mM}^{-1}[12]$. Lastly, $\mathrm{C}(\triangleright$ Equation 2$)$ was calculated as the ratio between and S400 (T400 center-of-mass speed) [21]:

$\mathrm{C}=\mathrm{E}_{\mathrm{tot}} \cdot \mathrm{S} 400^{-1}$

In addition, ES values were converted into metabolic power by the quotient of $\mathrm{E}_{\mathrm{tot}}$ and test time $(\mathrm{kW})$ and expressed as percentages [10].

\section{Kinematical parameters}

A stopwatch (HS-70W; Casio, Tokyo, Japan) was used to time performance of the T400. To obtain swimming-test images, six stationary (non-coplanar view and synchronized) video cameras (HDRCX260, Sony, Tokyo, Japan) were used, four below and two above the water. Nineteen body markers were used for three-dimensional reconstruction of the swimming movement [24] and calculation of the center of mass by e-zone method [25]. The calibrated space $(4.5 \times 1.0 \times 1.50 \mathrm{~m}$, central $10 \mathrm{~m}$ in the last $25 \mathrm{~m}$ of each $100 \mathrm{~m}$ of T400) determined the biomechanical reference coordinates ( $x$, horizontal; $y$, lateral; and z, vertical) for the calculation of the kinematic parameters. The accuracy of the digitalization and of the calibration procedure was $7.1,0.8$, and $5.3 \mathrm{~mm}$, respectively, for the $x, y$, and $z$ axes. Thus, all kinematic parameters were calculated determined by 3D kinematic analysis (Ariel Performance Analysis System, Ariel Dynamics Worldwide, Trabuca Canyon, CA, USA). The Direct Linear Transformation Algorithm was used for three-dimensional reconstruction and a digital low-pass filter at $4 \mathrm{~Hz}$ was used to smooth the data.

The $\$ 400$ was calculated by dividing the horizontal displacement of the center of mass in one stroke by the overall cycle duration in four laps (75-100, 175-200, 275-300 and 375-400-m) in the center of the pool. The IVV was defined as the coefficient of speed variation over one cycle (CV = SD/mean) [13].

\section{Statistical analyses}

The Shapiro-Wilk test of normality was applied. Means, standard deviations, and $95 \%$ confidence intervals were calculated. A multiple linear regression (MLR) was used to identify the relative contributions of factors that are associated with the T400 performance. Previously, correlations (Pearson's r) were applied between the T400 performance and the variables described. Then, only those variables that were statistically correlated to the T400 were entered in the MLR with the stepwise model. $R^{2}$ adjusted was identified and Fisher's exact test was used to identify the regression significance. To express the relative importance of each equation factor, the weights of the regression were converted to standardized regression coefficients. The Durbin-Watson test was used to analyze the independency between the residuals not explained by the regression generated. The significance level was set at $5 \%$. Descriptive statistical analysis was performed in IBM SPSS Statistics 21.

\section{Results}

- Table 1 shows the mean values, standard deviations, and confidence intervals $(95 \% \mathrm{Cl})$ of energetic metabolic contribution sources (energy in $\mathrm{kJ}$ and metabolic power in $\mathrm{kW}$ ) and $\mathrm{C}$. The results showed that the 400-m front-crawl test requires a high metabolic
- Table 1 Energetic parameters and contribution in mean \pm standard deviation (SD) and $95 \% \mathrm{Cl}$ (confidence interval) values in T400 ( $n=14)$.

\begin{tabular}{|l|r|r|l|}
\hline Energetic parameters & \multicolumn{1}{|c|}{ Mean } & \multicolumn{1}{l|}{ SD } & \multicolumn{1}{l|}{$(\mathbf{9 5} \% \mathbf{C l}$} \\
\hline $\mathrm{VO}_{2 \text { peak }}\left(\mathrm{ml} \cdot \mathrm{kg}^{-1} \cdot \mathrm{min}^{-1}\right)$ & 68.13 & 9.68 & $(62.53-73.72)$ \\
\hline $\mathrm{La}_{\text {peak }}\left(\mathrm{Mm} \cdot \mathrm{I}^{-1}\right)$ & 9.03 & 0.73 & $(8.61-9.46)$ \\
\hline AnAla $(\mathrm{kJ})$ & 30.00 & 2.28 & $(28.68-31.32)$ \\
\hline AnAla $(\mathrm{kW})$ & 0.10 & 0.01 & $(0.09-0.11)$ \\
\hline AnLa $(\mathrm{kJ})$ & 29.06 & 3.81 & $(26.85-31.26)$ \\
\hline AnLa $(\mathrm{kW})$ & 0.10 & 0.02 & $(0.09-0.11)$ \\
\hline Aer $(\mathrm{kJ})$ & 434.71 & 73.31 & $(392.38-477.04)$ \\
\hline Aer $(\mathrm{kW})$ & 1.44 & 0.26 & $(1.29-1.59)$ \\
\hline $\mathrm{E}_{\text {tot }}(\mathrm{kJ})$ & 493.77 & 76.15 & $(449.79-537.74)$ \\
\hline $\mathrm{E}_{\text {tot }}(\mathrm{kW})$ & 1.63 & 0.27 & $(1.48-1.79)$ \\
\hline $\mathrm{C}\left(\mathrm{kJ} \cdot \mathrm{m}{ }^{-1}\right)$ & 0.99 & 0.19 & $(0.88-1.10)$ \\
\hline
\end{tabular}

$\mathrm{VO}_{2 \text { peak }}\left(\mathrm{ml} \cdot \mathrm{kg}^{-1} \cdot \mathrm{min}^{-1}\right)$ : oxygen uptake peak values reached in T400; $\mathrm{La}_{\text {peak }}\left(\mathrm{Mm} \cdot \mathrm{I}^{-1}\right)$ : peak lactate concentration of T400; AnAla $(\mathrm{kJ}) /(\mathrm{kW})$ : alactic anaerobic contribution absolute values; AnLa (kJ)/ (kW): lactic anaerobic contribution absolute values; Aer $(\mathrm{kJ}) /(\mathrm{kW})$ : aerobic contribution absolute values; $E_{\text {tot }}(\mathrm{kJ}) /(\mathrm{kW})$ : total energy absolute values; $\mathrm{C}\left(\mathrm{kJ} \cdot \mathrm{m}^{-1}\right)$ : energetic cost.

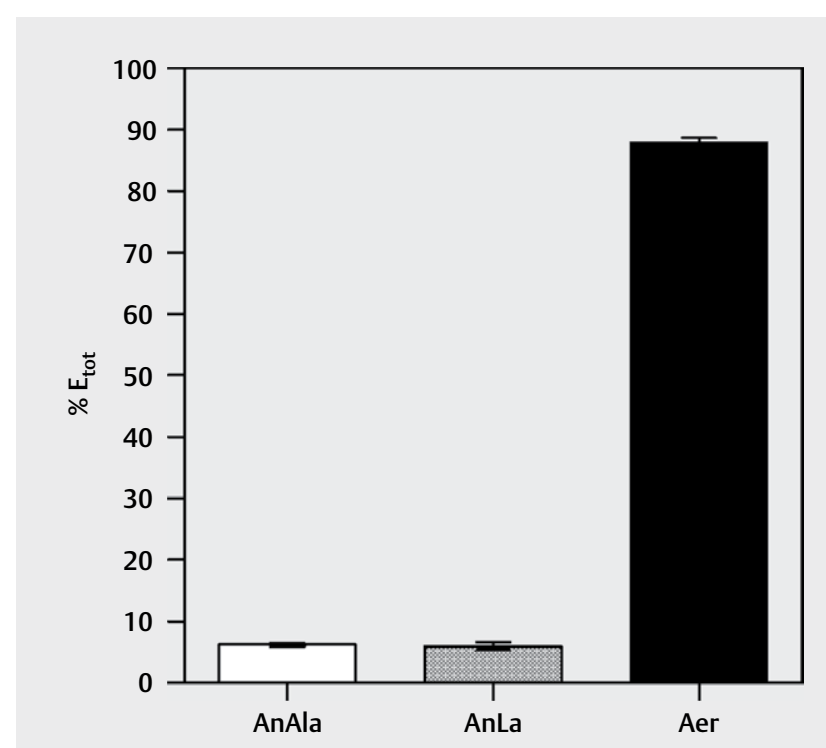

Fig. 1 Energetic contribution percentages (Aer: aerobic contribution, AnLa: anaerobic lactic contribution; AnAla: anaerobic alactic contribution; $n=14$ )

demand $\left(E_{t o t}\right)$ (mainly from Aer) with high C. > Fig. 1 reports the percentage values for energetic contribution to T400 performance. The means \pm SD were AnAla 6.19 $\pm 0.28 \%$; AnLa $5.97 \pm 0.63 \%$, and Aer $87.84 \pm 0.88 \%$. In addition to the high Aer, it can be seen that the anaerobic contributions summed represent $12 \%$.

- Table 2 shows means, standard deviations, and mean 95\% confidence intervals for the kinematical parameters (T400 time, $\mathrm{S} 400$, and IVV). The 400-m front-crawl test time-trial was lower because it was influenced by not being able to make turns and exits (due to the use of snorkel). - Table 3 shows the energetics and kinematical parameters correlated with performance in the T400 are 
- Table 2 Kinematics parameters in mean \pm standard deviation (SD) and $95 \% \mathrm{Cl}$ (confidence interval) values in T400 $(n=14)$.

\begin{tabular}{|l|r|r|l|}
\hline $\begin{array}{l}\text { Kinematics } \\
\text { parameters }\end{array}$ & Mean & SD & (95\%) IC \\
\hline $\mathrm{T} 400(\mathrm{~s})$ & 316.36 & 20.21 & $(300.21-315.23)$ \\
\hline $\mathrm{S} 400\left(\mathrm{~m} \cdot \mathrm{s}^{-1}\right)$ & 1.26 & 0.07 & $(1.18-1.35)$ \\
\hline $\mathrm{IVV}$ & 0.14 & 0.03 & $(0.12-0.16)$ \\
\hline
\end{tabular}

T400 (s): performance of $400-\mathrm{m}$ test; $\$ 400\left(\mathrm{~m} \cdot \mathrm{s}^{-1}\right)$ : mean center-of-mass speed of 400-m test; IVV: intracycle variation velocity of $400-m$ test.

- Table 3 Pearson's r correlation and significance level ( $p$-value) between energetics and kinematics parameters with T400 performance $(n=14)$.

\begin{tabular}{|l|l|}
\hline & $\mathbf{r}$ (p-value) \\
\hline $\mathrm{La}_{\text {peak }}\left(\mathrm{m} \cdot \mathrm{mol}^{-1} \mathrm{I}^{-1}\right)$ & $-0.60(0.02)$ \\
\hline Aer $(\mathrm{kJ})$ & $0.08(0.78)$ \\
\hline Aer $(\mathrm{kW})$ & $-0.40(0.15)$ \\
\hline Aer $(\%)$ & $0.29(0.30)$ \\
\hline AnLa $(\mathrm{kJ})$ & $-0.47(0.08)$ \\
\hline AnLa $(\mathrm{kW})$ & $-0.82(<0.001)$ \\
\hline AnLa $(\%)$ & $-0.46(0.09)$ \\
\hline AnALa $(\mathrm{kJ})$ & $-0.02(0.92)$ \\
\hline AnALa $(\mathrm{kW})$ & $-0.73(0.003)$ \\
\hline AnALa $(\%)$ & $-0.06(0.81)$ \\
\hline$E_{\text {tot }}(\mathrm{kJ})$ & $0.05(0.85)$ \\
\hline$E_{\text {tot }}(\mathrm{kW})$ & $-0.46(0.09)$ \\
\hline S400 $\left(\mathrm{m} \cdot \mathrm{s}^{-1}\right)$ & $-0.90(<0.001)$ \\
\hline IVV & $-0.34(0.23)$ \\
\hline
\end{tabular}

$\operatorname{La}_{\text {peak }}\left(\mathrm{Mm} \cdot \mathrm{I}^{-1}\right)$ : peak lactate concentration of T400; Aer $(\mathrm{kJ}) /(\mathrm{kW})$ : aerobic contribution absolute values; AnLa (kJ)/ (kW): lactic anaerobic contribution absolute values; AnAla (kJ)/(kW): alactic anaerobic contribution absolute values; $\mathrm{E}_{\text {tot }}(\mathrm{kJ}) /(\mathrm{kW})$ : total energy absolute values; $\mathrm{S} 400\left(\mathrm{~m} \cdot \mathrm{s}^{-1}\right)$ : mean center-of-mass speed of 400-m test; IVV: intracycle variation velocity of $400-\mathrm{m}$ test.

$\operatorname{La}_{\text {peak }}(r=0.60)$, S400 $(r=-0.90)$, AnLa $(k W, r=-0.82)$, and AnAla $(k W, r=-0.73)$ all with $p<0.05$. However, the predictors of performance through the linear regression were $\mathrm{S} 400$ and AnAla (kW).

- Fig. 2 shows T400 performance as a function of the $S 400$ and AnAla (KW). The data was distributed in a scatterplot using a linear function to estimate a possible relationship between theses parameters $\left(F_{2,11}=86.04 ; p<0.001\right.$; Durbin-Watson $\left.=1.80\right)$. In addition, these results indicate that the best performance in the T400 is determined by the high speed of the center of mass and by the anaerobic lactic contribution $\left(R^{2}=0.92\right)$. Thus, the equation generated for performance estimation by means of $\mathrm{S} 400\left(\mathrm{~m} \cdot \mathrm{s}^{-1}\right)$ and AnAla $(\mathrm{kW})$ is:

$\mathrm{T} 400(\mathrm{~s})=(-181.7 \times \mathrm{S} 400)+(-955.3 \times$ AnAla $)+640.5$

Where T400(s) is time trial for the T400, S400 the T400 center-ofmass speed, and AnAla (kW) the anaerobic alactic power.

\section{Discussion}

This study was designed to verify the relative contributions of parameters (ES, S400, and IVV) to the performance in the 400-m front crawl test. Firstly, it was necessary to describe the results of the energy and kinematical parameters. Subsequently, these were listed in an attempt to find which parameter(s) could explain the performance in 400-m front crawl test. T400 performance depends heavily on the aerobic system because the test lasts around $300 \mathrm{~s}$. It should be pointed that the swimmers were breathing through a snorkel during the test, to enable obtaining $\mathrm{VO}_{2}$ values, and this impairs turns and the dolphin kick phase after turns, thus increasing performance time but not impairing mean swimming speed or other kinematical parameters [26].

Energetic contributions can be expressed as work performed (in $\mathrm{kJ}$ ), metabolic power (in kW) and ES percentage values. All these measures help to provide a complete picture of energy balance. In the present study, Aer was $435 \mathrm{~kJ}, 1.44 \mathrm{~kW}$, and $88 \%$ of the ES. The aerobic system is the main source of the metabolic energy required in the T400 [6, 27]. In a 100-m front crawl test, the corresponding values were $\sim 90 \mathrm{~kJ}, 1.41 \mathrm{~kW}$, and $49 \%$ of Aer (calculated from data on C and speed) [28]. In a 200-m front crawl test, they were $211 \mathrm{~kJ}$, $1.49 \mathrm{~kW}$, and $65 \%$ of Aer [10]. In the T400, for young swimmers ( $\sim 15$ years old) Aer was reported as $331 \mathrm{~kJ}, 1 \mathrm{~kW}$, and $90 \%$ [7]. Thus, it is observed that the longer the distance, the greater the recruitment of aerobic metabolism. Differences in body mass, height, age, gender, years of experience, and training may influence the aerobic energy capacity.

In this study, the AnAla was $30 \mathrm{~kJ}(0.10 \mathrm{~kW})$. AnLa was $29 \mathrm{~kJ}$ $(0.10 \mathrm{~kW})$, and each system contributed $6 \%$ of the $E_{\text {tot }}$. The corresponding values for the 100-m front crawl test [20] were as follows: AnLa was $27 \mathrm{~kJ}, 0.42 \mathrm{~kW}$, and $21 \%$; and AnAla was $39 \mathrm{~kJ}, 0.60 \mathrm{~kW}$, and $30 \%$. For the 200-m front crawl test [10], AnLa was $43 \mathrm{~kJ}, 0.31$ $\mathrm{kW}$, and $25 \%$; and AnAla was $65 \mathrm{~kJ}, 0.46 \mathrm{~kW}$, and $10 \%$. Thus, as the distance increases, the anaerobic contribution in relation to the total energy decreases. The contribution of the anaerobic system $(\sim 12 \%)$ was lower in our sample than previously reported values, which were around $18 \%[11,29,30]$, but those studies analyzed swimmers with faster times and swimming speeds $\left(\sim 1.40 \mathrm{~m} \cdot \mathrm{s}^{1}\right)$ than our sample $\left(\sim 1.26 \mathrm{~m} \cdot \mathrm{s}^{-1}\right)$. Moreover those studies $[15,21,27]$ calculated oxygen consumption using the retro-extrapolation method and did not present AnAla results.

As pointed out above, ES results are influenced by the experimental and analytical procedures. A recent similar study [7] reported an anaerobic contribution of 10\% (7\% AnAla and 3\% AnLa) for the T400 in a sample of swimmers younger than those in our sample, with a mean speed of $1.20 \mathrm{~m} \cdot \mathrm{s}^{-1}$ and mean time of $\sim 320 \mathrm{~s}$. However, the sample of this study had men and women, which explains the slightly lower anaerobic contribution values compared to the present study. Estimates of AnAla may vary between studies $[10,12]$ depending on the relative value of body mass used. Although the T400 is predominantly an aerobic activity, it is necessary to stimulate the anaerobic energy sources during training. The anaerobic contribution to T400 performance, although low (12\%), is not negligible in competitive performance. An indirect test protocol to determine $\mathrm{ES}$ ( $\mathrm{VO}_{2}$ estimated using retro-extrapolation) indicated that anaerobic metabolism contributes between 20-30\% of the energy used in the T400 [6]. Furthermore Laffite, Vilas-Boas, Demarle, et al. [11] stated that the contribution of the anaerobic system to the first $100 \mathrm{~m}$ of the T400 is much higher ( 45\%, international level swimmers). However, T400 performance in the pre- 

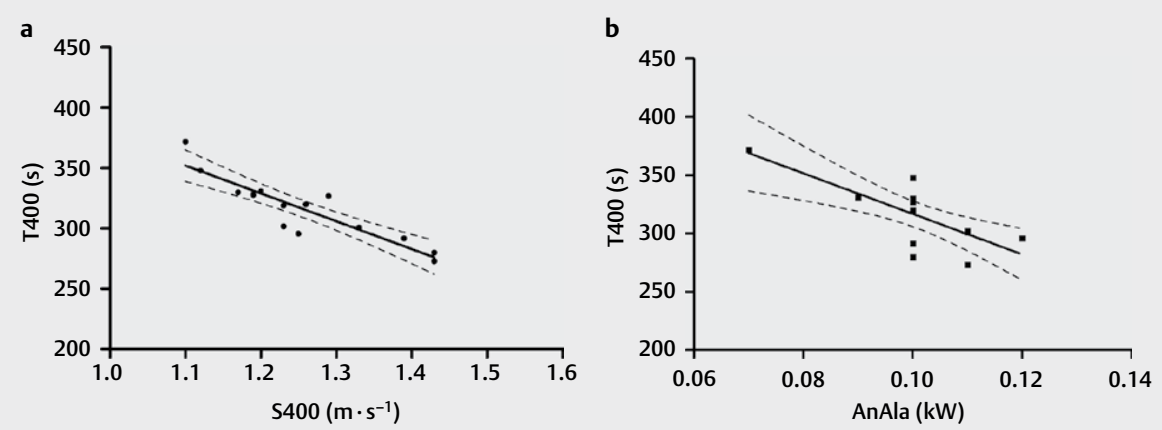

- Fig. 2 Scattergrams of T400 performance as a function of the a center of mass speed of 400 -m test (S400, m. $\left.\mathrm{s}^{-1}\right)$ and $\mathbf{b}$ alactic anaerobic contribution (AnAla, kW). Dashed line indicates the confidence interval (95\%).

sent study was worse when compared to the results of Rodríguez and Mader [6] and Laffite, Vilas-Boas, Demarle, et al. [11]. Because we collected gas directly, and the swimmers were not able to perform flip turns or undulatory underwater movements, this may have led to an underestimation of the anaerobic contribution.

Values for $C$ depend on the external and internal mechanical work and are influenced by hydrodynamic drag [31]. Reported C values for T400 are around 0.75 to $1.16 \mathrm{~kJ} \cdot \mathrm{m}^{-1}[10,14,32,33]$. We found an average $C$ of $0.99 \mathrm{~kJ} \cdot \mathrm{m}^{1}$ with a mean swimming speed of $1.26 \mathrm{~m} \cdot \mathrm{s}^{-1}$, which is similar to previous results $[10,13,30]$. One should consider that there is variation in the methods to obtain oxygen uptake values and in the fixed values used in AnLa and AnAla metabolism calculations. These differences may contribute to the differences in reported values for $\mathrm{C}$. In addition, age, gender, and the swimmer's technical level [31] may also influence $C$ values. Previous studies that used similar methods to ours reported $C$ $\sim 1.16 \mathrm{~kJ} . \mathrm{m}^{-1}$ for the $100-\mathrm{m}$ front crawl with a mean swimming speed of $1.58 \mathrm{~m} \cdot \mathrm{s}^{-1}$ [19], and $\sim 1.60 \mathrm{~kJ} \cdot \mathrm{m}^{-1}$ for the 200 -m front crawl with a mean swimming speed of $1.51 \mathrm{~m} \cdot \mathrm{s}^{-1}$ [10]. A recent longitudinal study of the T400 in young swimmers [7] reported a C of $\sim 0.92 \mathrm{~kJ} . \mathrm{m}^{-1}$ with a mean swimming speed of $1.20 \mathrm{~m} \cdot \mathrm{s}^{-1}$. Taking into account distance and speed effects, those results are similar to those presented here.

To our knowledge, this is the first study to have used 3D kinematic analyses to calculate IVV in the T400. A study that applied the same method (physiology and 3D kinematical) to the 200-m front crawl test obtained values of $0.22 \pm 0.03$ for a higher mean swim speed $\left(1.42 \pm 0.05 \mathrm{~m} \cdot \mathrm{s}^{-1}\right)$ than our sample achieved $\left(1.26 \pm 0.07 \mathrm{~m} \cdot \mathrm{s}^{-1}\right)$. Our IVV results are similar to previous results based on two-dimensional kinematical analyses [16] ( 0.14 in the 400-m race pace). Schnitzler, Seifert, Ernwein, et al. [16] found that in elite swimmers, IVV values varied little across swimming speeds and distances, because elite swimmers have sufficient technical ability to change their front crawl coordination in order to keep IVV and C low.

Interestingly, we found significant a correlation of anaerobic parameters (La, Anla and AnAla) with T400 performance. Thus, it may be likely that these parameters influence the $\$ 400$ and consequently performance. These possible relationships are scarce in the literature for the 400-m front crawl, except for one study [34] that used a different method (excess post-exercise oxygen consumption) to estimate the anaerobic contribution to T400 performance.
Positive correlations were found $(r=0.80$ and $r=0.44)$ between anaerobic contribution and performance, with the result being similar to that obtained in this study. In the present study, multiple linear regression indicated that performance is improved by reaching higher speeds and recruiting AnAla in the T400. It was expected that the Aer would also influence performance. However, this did not occur, possibly due to the homogeneity of the results related to aerobic contribution among the participants. All presented high values of oxygen consumption and thus the Aer, which is even important for performance in the T400, was not able to discriminate performance at this level. The AnaAla (kW) was a strong T400 performance predictor, confirming the hypothesis formulated.

Another possible explanation to consider is that for a higher swimming speed, anaerobic sources, mainly AnAla, contribute more to the $E_{\text {tot }}$ than in lower swimming speeds. In mid-distance races, this contribution is due to the extended time trial if we compare it to shorter events [35]. Therefore, this possible effect may have influenced the relationship with performance in T400. In addition, the specialist swimmers of this distance train to improve aerobic capacity and consequently performance. At the same time, the present study's results lead us to question whether coaches stimulate anaerobic power, and more specifically the alactic anaerobic power. It was identified that the swimmers with the highest AnAla power values were those with the highest average $\$ 400$. Therefore, this finding is important information for coaches and swimmers to review the application of this training content. However, more studies with a larger sample are needed to investigate the possible relationships between the sources of energy contribution in swimming (mainly anaerobic sources) in the 400-m front crawl test.

Therefore, some limitations of the study may be useful to inform and to conduct future research. The actual sample size precludes comparison between performance groups. In addition, 100-m sections of $400 \mathrm{~m}$ at steady speed refer to speeds reached throughout the T400. Thus, it would be possible to calculate the energy sources at each lap to estimate the energy balance throughout the test as performed in the study by Figueiredo, Zamparo, Sousa, et al. [10] in the 200-m front crawl test.

\section{Conclusions}

The results indicated a predominance of Aer in the T400, and high C and IVV. AnAla and S400 were strong T400 performance predic- 
tors, and together were able to explain $92 \%$ of the T400 performance. Thus, swimmers with a higher AnAla contribution obtained better performance in the T400. Hence, swimming training should stimulate both aerobic and anaerobic metabolism in order to improve T400 performance.

\section{Acknowledgements}

The authors thank all subjects who participated in this study and to the collaborators of the Aquatic Sports Research Group -UFRGS.

\section{Conflicts of Interest}

The authors declare that they have no conflicts of interest.

\section{References}

[1] Sousa A, Figueiredo P, Pendergast D, Kjendlie PL, Vilas-Boas JP, Fernandes RJ. Critical evaluation of oxygen-uptake assessment in swimming. Int J Sports Physiol Perform 2014; 9: 190-202

[2] Feitosa WG, Barbosa TM, Correia RDA, Castro FAS. Maximal oxygen uptake, total metabolic energy expenditure, and energy cost in swimmers with physical disabilities. Int J Perf Anal Spor 2019; 19: 503-516

[3] Zacca R, Azevedo R, Silveira RP, Vilas-Boas JP, Pyne DB, Castro FAS. Comparison of incremental intermittent and time trial testing in age-group swimmers. J Strength Cond Res 2017; 33: 801-810

[4] Costill D, Kovaleski J, Porter D, Kirwan J, Fielding R, King D. Energy expenditure during front crawl swimming: predicting success in middle-distance events. Int J Sports Med 1985; 6: 266-270

[5] Ribeiro J, Cadavid E, Baena J, Monsalvete E, Barna A, De Rose EH. Metabolic predictors of middle-distance swimming performance. $\mathrm{Br}$ J Sports Med 1990; 24: 196-200

[6] Rodríguez FA, Mader A. Energy systems in swimming. In: Seifert L, Chollet, Eds. World Book of Swimming From Science to Performance. New York: Nova; 2011: 225-240

[7] Zacca R, Azevedo R, Chainok P, Vilas-Boas JP, Castro FAS, Pyne DB, Fernandes RJ. Monitoring age-group swimmers over a training macrocycle: Energetics, technique, and anthropometrics. J Strength Cond Res 2018 doi:10.1519/jsc.0000000000002762

[8] Zamparo P, Swaine IL. Mechanical and propelling efficiency in swimming derived from exercise using a laboratory-based whole-body swimming ergometer. J Appl Physiol (1985) 2012; 113: 584-594

[9] Holmer I. Swimming physiology. Ann Physiol Anthropol 1992; 11: 269-276

[10] Figueiredo P, Zamparo P, Sousa A, Vilas-Boas JP, Fernandes RJ. An energy balance of the $200 \mathrm{~m}$ front crawl race. Eur J Appl Physiol 2011; 111: 767-777

[11] Laffite LP, Vilas-Boas JP, Demarle A, Silva J, Fernandes R, Billat VL. Changes in physiological and stroke parameters during a maximal 400-m free swimming test in elite swimmers. Can J Appl Physiol 2004; 29: Suppl S17-31

[12] Capelli C, Pendergast DR, Termin B. Energetics of swimming at maximal speeds in humans. Eur J Appl Physiol Occup Physiol 1998; 78: 385-393

[13] Barbosa TM, Bragada JA, Reis VM, Marinho DA, Carvalho C, Silva A]. Energetics and biomechanics as determining factors of swimming performance: Updating the state of the art. J Sci Med Sport 2010; 13 : 262-269

[14] Caputo F, MFMd Oliveira, Denadai BS, Greco CC. Intrinsic factors of the locomotion energy cost during swimming. Brazilian Journal of Sports Medicine 2006; 12: 399-404
[15] Figueiredo P, Pendergast DR, Vilas-Boas JP, Fernandes R]. Interplay of biomechanical, energetic, coordinative, and muscular factors in a 200 m front crawl swim. Biomed Res Int 2013; 2013: 897232

[16] Schnitzler C, Seifert L, Ernwein V, Chollet D. Arm coordination adaptations assessment in swimming. Int J Sports Med 2008; 29: 480-486

[17] Harriss DJ, Macsween A, Atkinson G. Standards for ethics in sport and exercise science research: 2020 update. Int J Sports Med 2019; doi:10.1055/a-1015-3123

[18] Özyener F, Rossiter H, Ward S, Whipp BJ. Influence of exercise intensity on the on-and off-transient kinetics of pulmonary oxygen uptake in humans. J Physiol 2001; 533: 891-902

[19] De Jesus K, Guidetti L, Vilas-Boas J, Vilas-Boas JP, Baldari C, Fernandes $\mathrm{RJ}$. Which are the best $\mathrm{VO} 2$ sampling intervals to characterize low to severe swimming intensities? Int J Sports Med 2014; 35: 1030-1036

[20] Ribeiro ], Figueiredo P, Sousa A, Monteiro J, Pelarigo J, Vilas-Boas JP, Toussaint HM, Fernandes RF. VO(2) kinetics and metabolic contributions during full and upper body extreme swimming intensity. Eur J Appl Physiol 2015; 115: 1117-1124

[21] DiPrampero P. The energy cost of human locomotion on land and in water. Int J Sports Med 1986; 7: 55-72

[22] Zamparo P, Capelli C, Pendergast D. Energetics of swimming: a historical perspective. Eur J Appl Physiol 2011; 111: 367-378

[23] Binzoni T, Ferretti G, Schenker K, Cerretelli P. Phosphocreatine hydrolysis by 31P-NMR at the onset of constant-load exercise in humans. J Appl Physiol (1985) 1992; 73: 1644-1649

[24] McCabe CB, Psycharakis S, Sanders R. Kinematic differences between front crawl sprint and distance swimmers at sprint pace. J Sports Sci 2011; 29: 115-123

[25] Deffeyes ], Sanders R. Elliptical zone body segment modellng software: digitising, modellng and body segment parameter calculation. In: ISBS-Conference Proceedings Archive. 2008;

[26] Ribeiro ], Figueiredo P, Guidetti L, Alves F, Toussaint H, Vilas-Boas JP, Baldari C, Fernandes RJ. AquaTrainer ${ }^{\circledR}$ snorkel does not increase hydrodynamic drag but influences turning time. Int J Sports Med 2016; 37: 324-328

[27] Meira O, Reis VM, Silva AJ, Carneiro AL, Reis AM, Aidar F. Breathing frequency along the $400 \mathrm{~m}$ freestyle: association with pratice. Motricidade 2008; 4: 57-66

[28] Ribeiro J, Toubekis AG, Figueiredo P, de Jesus K, Toussaint HM, Alves F, Vilas-Boas JP, Fernandes RJ. Biophysical determinants of front-crawl swimming at moderate and severe intensities. Int J Sports Physiol Perform 2017; 12: 241-246

[29] Ring S, Mader A, Wirtz W, Wilke K. Energy metabolism during sprint swimming.In: Troup JP, Hollander AP, Strasse D, Trappe SW, Cappaert JM, Trappe TA, Eds. Biomechanics and Medicine in Swimming VII. London: E \& FN Spon; 1996: 177-184

[30] Zamparo P, Capelli C, Cautero M, Di Nino A. Energy cost of front-crawl swimming at supra-maximal speeds and underwater torque in young swimmers. Eur J Appl Physiol 2000; 83: 487-491

[31] Barbosa TM, Fernandes RJ, Keskinen KL, Vilas-Boas JP. The influence of stroke mechanics into energy cost of elite swimmers. Eur J Appl Physiol 2008; 103: 139-149

[32] Chatard J, Lavoie J, Lacourl J. Analysis of determinants of swimming economy in front crawl. Eur J Appl Physiol Occup Physiol 1990; 61: 88-92

[33] Fernandes R, Billat V, Cruz A, Colaço PJ, Cardoso CS, Vilas-Boas JP. Does net energy cost of swimming affect time to exhaustion at the individual's maximal oxygen consumption velocity? J Sports Med Phys Fitness 2006; 46: 373-380

[34] Kalva-Filho C, Campos E, Andrade V, Silva A, Zagatto AM, Lima M, Papoti M. Relationship of aerobic and anaerobic parameters with 400 m front crawl swimming performance. Biol Sport 2015; 32: 333

[35] Sousa A, Figueiredo P, Zamparo P, Vilas-Boas JP, Fernandes RJ. Anaerobic alactic energy assessment in middle distance swimming. Eur J Appl Physiol 2013; 113: 2153-2158 